\title{
A Digital Maturity Model for Telecommunications Service Providers Omar Valdez-de-Leon
}

\author{
'An organization's capabilities become its disabilities" \\ when disruptive innovation is afoot. \\ Clayton Christensen \\ Professor, business consultant, and author \\ In The Innovator's Dilemma
}

\begin{abstract}
Industries across the spectrum are being faced with a fundamental change: digital transformation. The telecommunications industry is no exception. For communications service providers, this transformation started some time ago with the emergence of so-called over-the-top (OTT) services such as WhatsApp and Skype. However, in spite of such transformation being underway, there is a lack of frameworks and tools to help communications service providers navigate such radical change. This article presents the findings of a research project to develop such a framework: the digital maturity model for telecommunications service providers. The model aims to offer a structured view of digital transformation that is specific to the context and challenges of the telecommunications industry and that can be used as a standard to help communications service providers benchmark themselves against peers or themselves as they advance their transformation. This article describes the need for the model and the methodology used to develop it, and it offers recommendations on how to use the model and further develop it as our understanding of digital transformation evolves.
\end{abstract}

\section{Introduction}

Communications service providers are being faced with a deep transformation that is taking them from being providers of traditional communication services (e.g., voice, SMS) into providers of digital services (e.g., music, mobile TV, cloud services, Internet of Things) This digital transformation - the use of technology such as analytics, mobility, social media, and smart embedded devices to improve the performance or reach of an enterprise (Westerman et al., 2011) - also requires communications service providers to digitize the way they serve their customers throughout the entire customer lifecycle. Thus, the transformation is disruptive; it affects not only customer relationships, but internal processes and value propositions as well (Westerman et al., 2011).

A number of factors are identified as key drivers for digital transformation, including:

- Technological advancement: everything is being connected to the Internet or is being digitized. Examples of this include connected vehicles and the digitization of money.
- New breeds of firms providing digital services that utilize the infrastructure of communications service providers (e.g., mobile networks) yet appropriate most of the value generated. Examples include firms such as Spotify and WhatsApp.

- A change in customer expectations, which are being molded towards an always-connected, personalized lifestyle and digitized services.

- The commoditization of traditional communication services and consequent revenue flat-lining or outright decline (see Kendall, 2014).

Two examples help illustrate this transition: AT\&T (att.com) in the United States and Rogers (rogers.com) in Canada. In 2013, AT\&T launched a completely new service for home security monitoring, which has since become a case study on how to successfully move into digital services. In 2014, Rogers launched a program with the aim of transforming the customer experience by digitizing the entire customer lifecycle. Rogers has reportedly managed to drastically transform customer experience as shown by a significant increase in the 


\section{A Digital Maturity Model for Telecommunications Service Providers}

\section{Omar Valdez-de-Leon}

number of customer interactions happening through digital channels, drastic improvements in customer satisfaction metrics, and reductions in customer complaints (Deloitte, 2016). However, these two examples appear to be exceptions rather than the rule, and most communications service providers are still struggling to figure out their transformation journey.

Such transformations go deep into every aspect of the businesses and operating models of communications service providers, yet there is a lack of tools and guidelines to help operators negotiate such change. Indeed, several researchers (e.g., Friedrich et al., 2015; Kuebel et al., 2014; Ovum, 2014) have shown that communications service providers are already committed and are taking steps towards digital transformation, but lack a clear path or guide. They all are taking divergent routes, in many cases changing course as they "try and learn" (Friedrich et al., 2015).

To navigate their digital transformation journey in a more confident and structured manner, these organizations look to existing frameworks, including seminal works in IT-enabled business transformation (e.g., Venkatraman, 1994) as well as more recent developments in digital transformation practice (e.g., Gerbert et al., 2015; McKinsey, 2015; Westerman et al., 2012). These frameworks offer a good structure and understanding of the digital challenge; however, they also tend to be too general and high-level in their coverage. The reason for this is likely to be that all have been designed to be generic in nature to apply to any industry. None of these models are specific to the telecommunications industry and as such are not designed to offer specific guidance to build a telecommunications-specific pathway to digital transformation.

A model that fills that gap is needed. Such a model should:

\section{Offer a structured view of digital transformation.}

2. Be comprehensive enough to cover all aspects of digital transformation.

3. Be specific to the context and challenges that communications service providers are facing.

4. Not only describe the current situation but also offer a view of what a more advanced, digital communications service provision looks like.
5. Be able to be used as an industry standard to help communications service providers benchmark themselves against peers or themselves as they advance their transformation.

The model presented here - the digital maturity model for telecommunications service providers - is intended to fill this gap. This article will first describe the methodology used to design and develop the model. Next, it will introduce the model, including its constituent dimensions and levels of maturity. Finally, the article will explain how it can be used in practice and further developed.

\section{Methodology}

In developing the model, a three-stage approach was followed, based on the best-known practice in the development of these type of models (Becker \& Knackstedt, 2009; De Bruin et al., 2005):

\section{A clear definition of the scope of the model.}

\section{An initial design or architecture of the model.}

3. An iterative approach to validate (with experts in the field) the design of the model.

\section{Defining the scope}

From the outset, the focus of the model was very clear: the digital transformation of communications service providers. More specifically, the scope of the digital maturity model is to help communications service providers to identify their current position in a digital maturity scale and be able to define a vision and a plan for moving up that maturity spectrum.

\section{Designing the initial model}

The design stage began with a comprehensive review of the relevant literature, case studies from several industries, and interviews with subject matter experts. These activities formed the basis for the identification of a set of key elements of digital transformation, which in turn resulted in a multi-dimensional model. The seven dimensions that comprise the model are depicted in Figure 1.

A progressive, multi-staged approach to transformation was then integrated into the model. The objective was to go beyond a plain low-medium-high notion and create a maturity scale that was more nuanced (reflecting the actual challenge) and industry-specific - 


\section{A Digital Maturity Model for Telecommunications Service Providers}

\section{Omar Valdez-de-Leon}

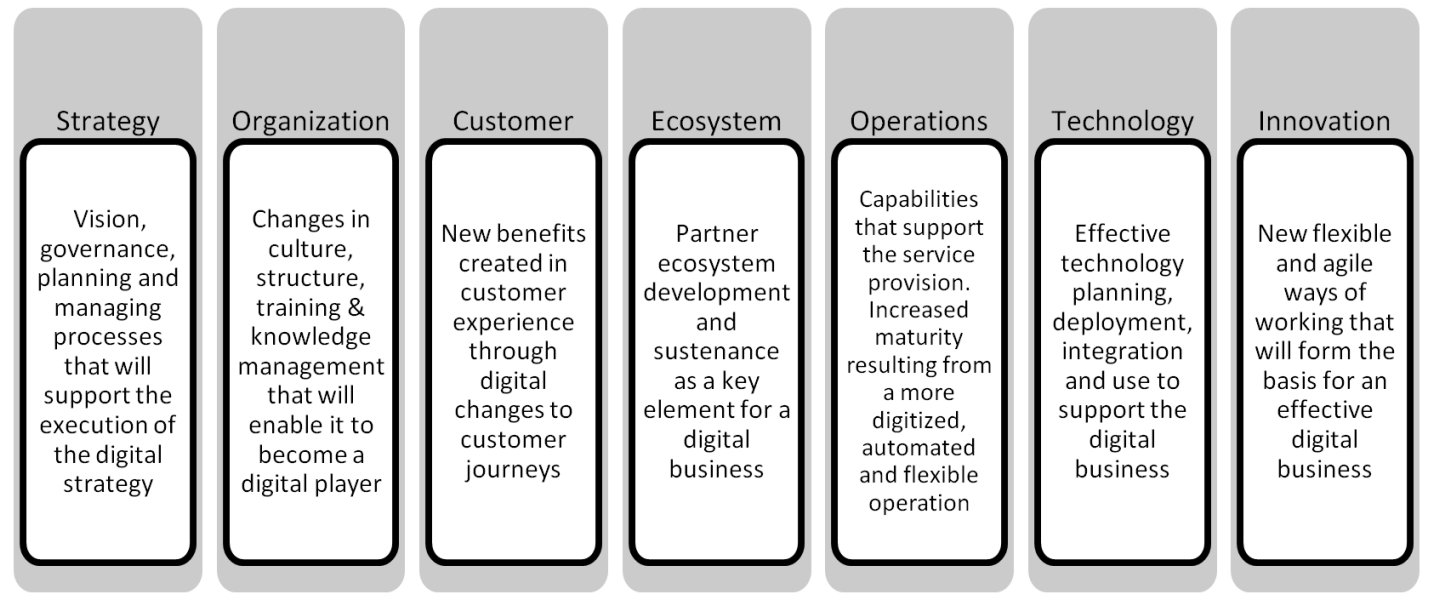

Figure 1. The initial structure and seven dimensions of the digital maturity model for telecommunications service providers

one that had high granularity without becoming too complex. Five levels of maturity were selected and integrated into the model skeleton, or outline, which included the seven dimensions (see Figure 2).

\section{Detailing and validating the model}

Next, an initial set of characteristics for each element in the matrix was defined. This step included a review of existing literature, examination of other available models, and input from experienced practitioners in the subject matter. Once a first draft of the model was completed, the final step was to take this draft to an external group of experts for them to scrutinize, criticize, and help further develop into a fully-fledged maturity model.
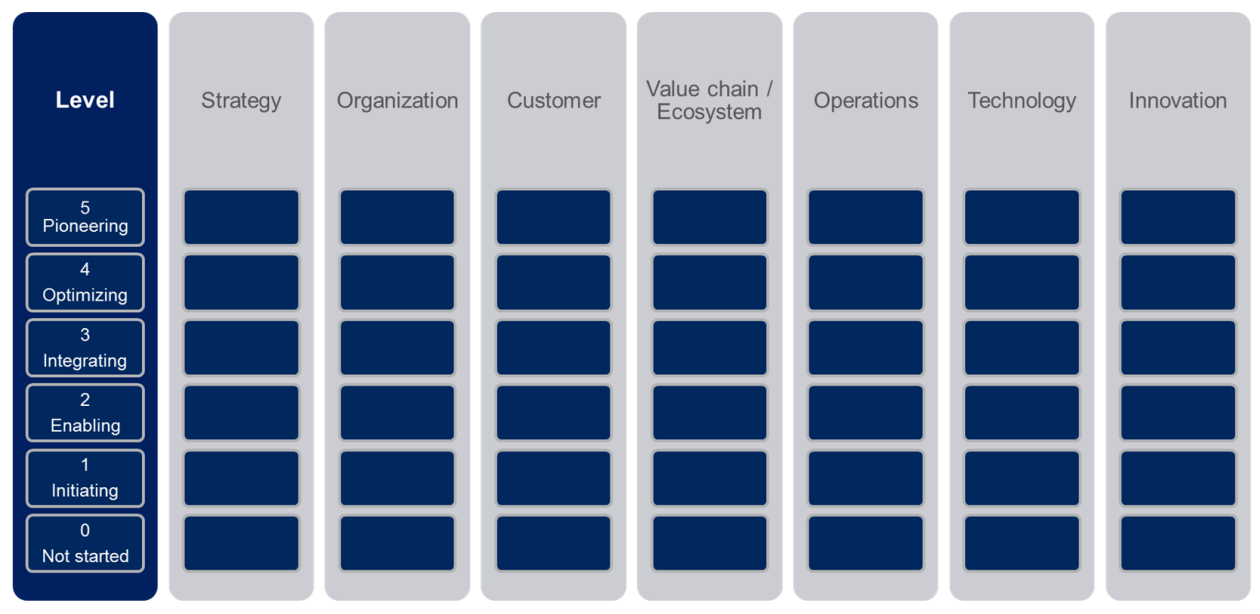

Figure 2. Initial outline of the digital maturity model for telecommunications service providers 


\section{A Digital Maturity Model for Telecommunications Service Providers}

Omar Valdez-de-Leon

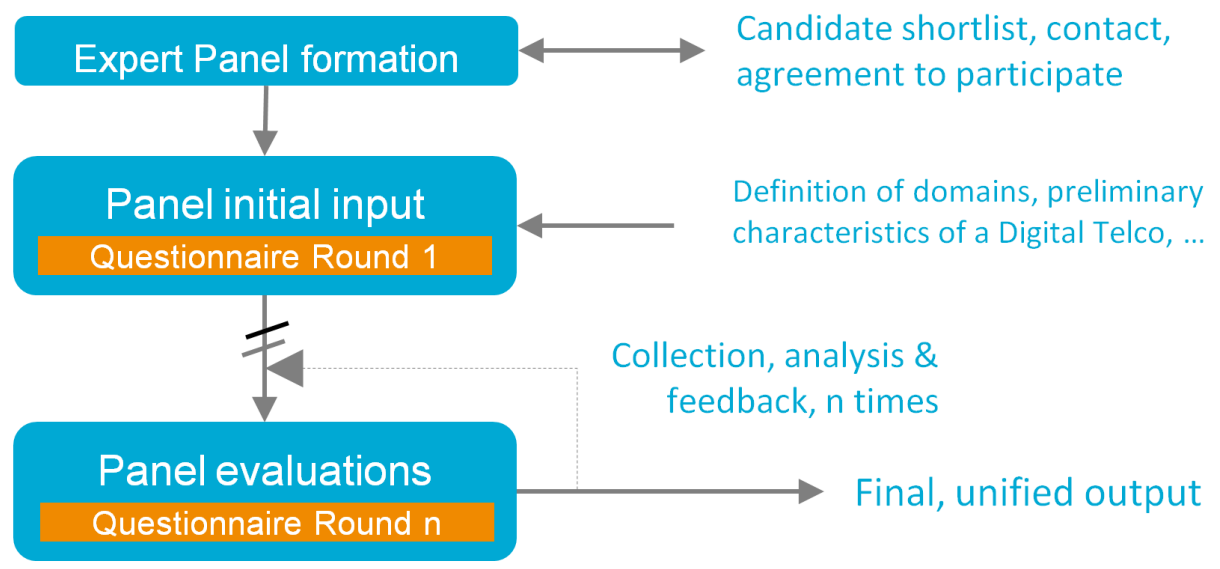

Figure 3. The Dephi method

\section{The Model}

The outcomes of the Delphi study included:

1. The definition of an overall maturity model with clearly defined dimensions and levels of maturity (see Figure 4 and Appendix 1).

2. The establishment of a set of characteristics that digital communications service providers are expected to demonstrate at defined levels of maturity for each of the dimensions that comprise the model.

\section{Dimensions}

The seven dimensions of the final model (refined and reordered through the model development process) are as follows:
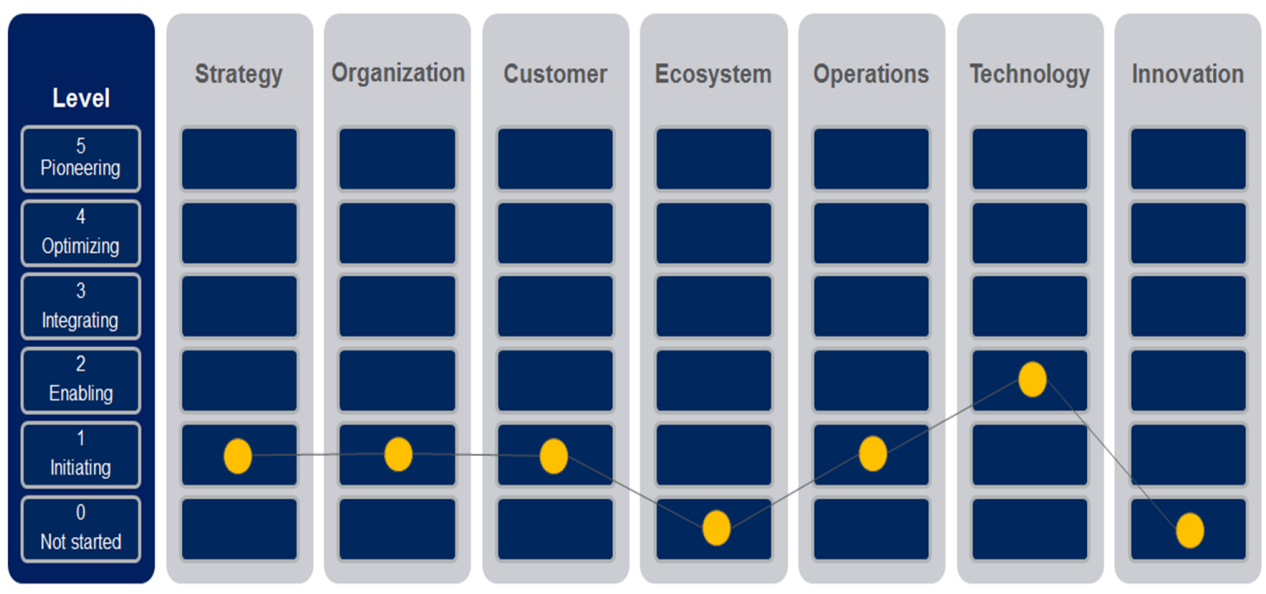

Figure 4. The completed digital maturity model for telecommunications service providers showing a hypothetical organization's maturity levels for each of the seven dimensions 


\section{A Digital Maturity Model for Telecommunications Service Providers}

\section{Omar Valdez-de-Leon}

5. Operations: Focusing on the capabilities that support the service provision. Increased maturity within this dimension demonstrates a more digitized, automated, and flexible operation.

6. Ecosystem: Signifying partner ecosystem development and sustenance as a key element for a digital business.

7. Innovation: Focusing on the capabilities that enable more flexible and agile ways of working that will form the basis for an effective digital business.

The dimensions aim to cover the vital areas of the business that are impacted and in turn impact digital transformation. As discussed above, the dimensions were the result of extensive research and insight from practitioners in the subject. Remarkably, throughout the study, two dimensions came up frequently as critical but were frequently underestimated in their importance in digital transformation: Ecosystem and Innovation. The importance of these two areas is ostensibly owing to the dynamic nature of digital technologies and the importance of continuous innovation, going beyond the boundaries of one single firm. For this reason, the two dimensions are distinguished from one another in the model.

\section{Maturity levels}

Maturity in each dimension is assessed across five levels (plus a default level zero reflecting a state of inaction). In order of decreasing maturity, these levels include:

5. Pioneering: The organization is breaking new ground and advancing the state of the practice within the dimension.

4. Optimizing: The organization's digital initiatives within the dimension are being fine-tuned and used to further increase overall performance.

3. Integrating: The organization's initiatives are being integrated across the organization to support end-toend capabilities.

2. Enabling: The organization is implementing initiatives within the dimension that will form the foundation of its digital business.

1. Initiating: The organization has decided to move toward a digital business and is taking initial steps in that direction.

0. Not started: The organization has not taken any steps to transform.
The levels represent the progression stages of a communications service provider in its digital transformation journey. Each level includes a set of characteristics (see full details in Appendix 1) that a business must demonstrate in terms of implementations, investments, or established capabilities in order to be situated at that particular level. Each level builds on the previous one. As the organization implements and integrates the various changes that are pertinent to its digitization journey, the maturity rating would rise across the applicable dimensions.

\section{Use of the model}

The model aims to depict the level of maturity of a communications service provider at a given point in time. It also provides a vision of what a more mature digital business looks like. However, the model is not prescriptive as to what is the "best way" to move up in the maturity scale. It also does not suggest that Level 5 is a requirement for all organizations. Instead, it is an implementation model where the levels are a snapshot of the extent of implementation.

It is indeed of vital importance for each organization to define the level of maturity it wants to attain, in line with its business ambitions, context, resources, and timeline. The model can be used to define the current level of maturity, and as a guide through the transformation journey in the desired timeframe. The model can also be used as a benchmarking tool to evaluate an organization's own position against a competitor or a peer, or between operating companies within the same group. Finally, the model can be used to evaluate progress and to assess results of previous investments. In summary, examples of how the model can be used are as follows:

- to provide a structured view of current and target positions (e.g., where do we want to be in five years?)

- as a benchmarking tool

- to identify deficiencies in an area that may adversely affect the overall effectiveness of transformation efforts

- as a support tool to define next steps and priorities in digital transformation

- to assess whether the organization has properly prioritized and ordered implementation efforts, or whether it has "the cart before the horse"

- to assess or confirm results from previous investments 


\title{
A Digital Maturity Model for Telecommunications Service Providers
}

\author{
Omar Valdez-de-Leon
}

\section{Conclusion}

The digital maturity model described in this article was developed to help telecommunications service providers in their digital transformation journey. The motivation for developing such model originated from the clear absence of industry-specific tools available to guide such transformations. The resulting model is intended as a tool to gauge digital maturity at a particular point in time and to help develop a vision and a roadmap for digital transformation. It is recommended that practitioners adopt the model as a central component of a toolbox for digital transformation.

The model is intended as a tool to define current and target states of maturity; however, it is not prescriptive as to suggest a best way to achieve the target state. As such, it is suggested that complementary tools should be developed to help define the "best practices" and further develop the framework. For example, such best practices can be developed based on in-depth empirical evidence as more communications service providers embark on journeys of digital transformations, and as successes and failures become better understood and documented.

Finally, although the model was designed for telecommunications services providers, the framework may be of interest to other industries, especially those in services. Therefore, industry-specific adaptations are advised to make the model fit for the particular industry.

\section{Acknowledgments}

This research project was supported by Ericsson, where the author works as a Senior Consultant within the Global Consulting and Systems Integration practice. The author would like to thank and acknowledge the contributions of a number of people that agreed to take part in an expert panel. In alphabetical order, the panel members include:

- Alejandro Maroto, Global Head of Innovation \& Business Development, Telefonica

- Giorgio Santini, Director EMEA, Gartner

- Dr. Mark H Mortensen, Research Director, Digital Economy Platforms Research, Analysis Mason

- Dr. Mischa Dohler, Professor \& Head of the Centre for Telecommunications Research, King's College London

- Richard George, Director of Digital, Eir

- Simone Bruschi, Head of Digital Banking - Retail, Banca Monte dei Paschi di Siena

- Simon Torrance, CEO of Metaflight, Senior Advisor at Analysis Mason and founder of Telco 2.0

- Thao Tu, Head of Business Consulting at Ericsson

Thank you also to those that decided to remain anonymous and those that indirectly contributed through discussions and advice. 


\section{A Digital Maturity Model for Telecommunications Service Providers}

\section{About the Author}

Omar Valdez-de-Leon is a Senior Consultant within the Global Consulting and Systems Integration practice at Ericsson. He is a practitioner in the area of innovation and digitization of products and services and, over the years, he has worked across the IT and telecommunications industry in companies such as Bosch, Logica-CGI, Elster, Vodafone, and Ericsson, with a focus on new business initiatives grounded in emerging technologies. He holds an MSc in Technology \& Innovation Management from SPRU in the University of Sussex, UK, and an MBA from Manchester Business School.

Citation: Valdez-de-Leon, O. 2016. A Digital Maturity Model for Telecommunications Service Providers.

Technology Innovation Management Review, 6(8): 19-32.

http://timreview.ca/article/1008

Keywords: digitization, business, digital, maturity model, telecommunications, innovation, disruptive technologies, digital transformation, business transformation

\section{References}

Becker, J., \& Knackstedt, R. 2009. Developing Maturity Models for IT Management - A Procedure Model and its Application. Business \& Information Systems Engineering, 1(3): 213-222. http://dx.doi.org/10.1007/s12599-009-0044-5

De Bruin, T., Freeze, R., Kaulkarni, U., \& Rosemann, M. 2005. Understanding the Main Phases of Developing a Maturity Assessment Model. Paper presented at the 16th Australasian Conference on Information Systems, November 29-December 2, 2005, Sydney.

Deloitte. 2016. Digital Transformation for Telecom Operators: Adapting to a Customer-Centric, Mobile-First World. London: Deloitte MCS Limited.

http://www2.deloitte.com/content/dam/Deloitte/us/Documents/ technology-media-telecommunications/deloitte-uk-digitaltransformation-telecom.pdf

Friedrich, R., Hall, S., \& El-Darwiche, B. 2015. Industry Perspectives: 2015 Telecommunications Trends. Strategy\&. Accessed August 1, 2016:

http://www.strategyand.pwc.com/perspectives/2015-

telecommunications-trends

Gerbert, P., Gauger, C., \& Steinhauser, S. 2015. The Double Game of Digital Strategy. BCG Perspectives, October 16, 2015. Accessed August 1: 2016:

https://www.bcgperspectives.com/content/articles/business-unitstrategy-big-data-advanced-analytics-double-game-digitalstrategy/

Kuebel, H., Limbach, F., \& Zarnekow, R. 2014. Business Models of Developer Platforms in the Telecommunications Industry - An Explorative Case Study Analysis. In Proceedings of the 47th Hawaii International Conference on System Science, January 6-9, 2014. http://dx.doi.org/10.1109/HICSS.2014.486

McKinsey. 2015. Digital Quotient. McKinsey\&Company: Digital McKinsey. Accessed August 1, 2016: http://www.mckinsey.com/business-functions/digitalmckinsey/how-we-help-clients/digital-quotient

Okoli, C., \& Pawlowski, S. D. 2004. The Delphi Method as a Research Tool: An Example, Design Considerations and Applications. Information \& Management, 42(1): 15-29. http://dx.doi.org/10.1016/j.im.2003.11.002

Ovum. 2014. Digital Operator Strategies: Market Segments, Structure, Business Models and Monetization. London: Ovum.

Kendall, P. 2014. Global Mobile Service Revenue to Stagnate at \$1 Trillion Mark. Milton Keynes, UK: Strategy Analytics.

Venkatraman, N., 1994. IT-Enabled Business Transformation: From Automation to Business Scope Redefinition. Sloan Management Review, 35(2): 73-87.

Westerman, G., Tannou, M., Bonnet, D., Ferraris, P., \& McAfee, A. 2012. The Digital Advantage: How Digital Leaders Outperform Their Peers in Every Industry. Capgemini Consulting \& MIT Sloan Management. 


\title{
A Digital Maturity Model for Telecommunications Service Providers
}

\author{
Omar Valdez-de-Leon
}

Appendix 1. Characteristics of the digital maturity model for telecommunications service providers (Page 1 of 7)

\section{Strategy}

This dimension represents vision, governance, planning, and management processes that will support the implementation of the digital strategy.

Level 1 - Initiating

The organization has decided to move toward a digital business and is taking initial steps in that direction.

S1.1 The organization has defined an initial digital vision, albeit at this point it is mostly "siloed" and focused on incremental operational improvements.

S1.2 Some proof-of-concept projects have been authorized at a departmental level to experiment with digital tools (e.g., self-service apps).

Level 2 - Enabling

The organization is implementing initiatives within the dimension that will form the foundation of its digital business.

S2.1 A digital strategy that incorporates most elements of this digital maturity model is signed-off at CxO level.

S2.2 Formal investments aligned to the digital strategy have been approved.

S2.3 Digital leadership have been appointed to drive transformation

S2.4 Budgets are incorporating digital targets.

Level 3 - Integrating

The organization's initiatives are being integrated across the organization to support end-to-end capabilities.

S3.1 A common digital strategy is shared across the whole organization at all levels.

S3.2 Investments have been authorised at CXO level for overall digital transformation.

S3.3 Digital initiatives are being implemented across the organization, including cross-departmental projects.

S3.4 Budgets, key performance indicators and performance metrics across the organization include a digital element, including common (inter-departmental) targets.

S3.5 First set of digital services are in the roadmap/delivered, including partnerships with digital vendors (e.g., fleet management, IaaS).

S3.6 Digital revenues are now being specifically recorded, although these might not yet be particularly large.

Level 4 - Optimizing

The organization's digital initiatives within the dimension are being fine-tuned and used to further increase overall performance.

S4.1 Digital strategy is well developed and drives the organization's direction and investments.

S4.2 Digital is a core competence in the organization.

S4.3 New business models are being implemented with pure digital elements.

S4.4 Digital strategy is being shared and reviewed with all stakeholders, including external partners.

S4.5 Digital strategy is no longer owned by a dedicated team but it is an inherent part of activities across the organization

S4.6 New digital services are becoming a significant share of total revenues $(\sim 5 \%)$.

Level 5 - Pioneering

The organization is breaking new ground and advancing the state of the practice within the dimension.

S5.1 The digital strategy has for some time been driving management and investment decisions.

S5.2 The organization is now capitalizing on previous investments and transformation efforts to generate completely new revenue streams based on digital capabilities and digital business models.

S5.3 Digital businesses provide sufficient revenue streams to enable continued investment in new digital initiatives.

S5.4 Digital services account for a significant $(>10 \%)$ share of total revenues. 


\title{
A Digital Maturity Model for Telecommunications Service Providers
}

\author{
Omar Valdez-de-Leon
}

Appendix 1. Characteristics of the digital maturity model for telecommunications service providers (Page 2 of 7 )

\section{Organization}

This dimension focuses on changes in communications, culture, structure, training, and knowledge management within the organization that will enable it to become a digital player.

Level 1 - Initiating

The organization has decided to move toward a digital business and is taking initial steps in that direction.

O1.1 The organization has articulated the need for digital transformation.

O1.2 The need for digital competencies has been identified and a general development plan is being defined.

O1.3 Initial investments are being made to develop digital competencies, including training programmes.

O1.4 Recruitment of select "experts" to bring needed skills is ongoing, often in isolated teams.

Level 2 - Enabling

The organization is implementing initiatives within the dimension that will form the foundation of its digital business.

O2.1 The organization has a vision for digital transformation, which begins to drive change towards a digitallysavvy workforce.

O2.2 Digital units/teams are being created to explore digital opportunities.

O2.3 Training and compensation schemes are being adapted to align with the digital strategy.

O2.4 Digital services are supported by a specific sales team.

Level 3 - Integrating

The organization's initiatives are being integrated across the organization to support end-to-end capabilities.

O3.1 Management is continuously communicating the digital strategy and advances in its implementation across the whole organization.

O3.2 Digital strategy is driving corporate change, including organizational structure and key performance indicators.

O3.3 Digital initiatives incorporate people from several functions and departments, as well as external partners.

O3.4 Performance and compensation systems across the organization incorporate digital elements.

O3.5 Global processes are set to promote the transfer of global/central digital knowledge towards the Operating Businesses (OpCos).

Level 4 - Optimizing

The organization's digital initiatives within the dimension are being fine-tuned and used to further increase overall performance.

O4.1 Digital is fully embedded in the corporate culture.

O4.2 Digital capabilities are well developed and partnerships are continuously formed to access new ones.

O4.3 A well-defined personnel development strategy is in place, including when to train, outsource, or acquire digital capabilities.

O4.4 Key performance indicators for sales are now mainly driven by digital services.

Level 5 - Pioneering

The organization is breaking new ground and advancing the state of the practice within the dimension.

O5.1 Collaboration with other ecosystem partners is well established, generating service innovation that is ahead of competition.

O5.2 The organization is flexible and easily adapts to changes in the market in a more agile way than competitors.

O5.3 The organization is focused on digital innovation. 


\title{
A Digital Maturity Model for Telecommunications Service Providers
}

\author{
Omar Valdez-de-Leon
}

Appendix 1. Characteristics of the digital maturity model for telecommunications service providers (Page 3 of 7 )

\begin{abstract}
3. Customer
This dimension focuses on customer participation and empowerment, as well as new benefits created in customer experience through digital transformation of customer touch points.
\end{abstract}

Level 1 - Initiating

The organization has decided to move toward a digital business and is taking initial steps in that direction.

C1.1 Basic self-help tools (e.g., online portals, forums) are available to customers.

C1.2 Initial pilots of new digital tools such as self-service apps and social media support are being conducted.

C1.3 Initiatives and requirements to expand customer interaction beyond basic app-based self-support have been identified.

C1.4 Basic e-commerce capabilities are being implemented to drive calls to purchase online.

Level 2 - Enabling

The organization is implementing initiatives within the dimension that will form the foundation of its digital business.

C2.1 An omni-channel vision has been fully articulated (although not necessarily completely executed).

C2.2 New digital customer engagement tools are being implemented supporting the customer lifecycle.

C2.3 Customer experience and usage data is actively collected and used to assist customer support and service improvements.

C2.4 New digital services (typically from third parties) are being made available to customers, albeit not yet as part of an integral "multi-product" service.

Level 3 - Integrating

The organization's initiatives are being integrated across the organization to support end-to-end capabilities.

C3.1 An omni-channel vision is well under-way throughout customer-facing operations (e.g., from physical shops through to online to mobile and call centres).

C3.2 Customers can not only access support and information; service self-configuration tools are also available across channels.

C3.3 Customer experience and usage data is routinely collected across all channels and shared across organizational functions (e.g., marketing, product management, customer support, network operations).

C3.4 Customers can bundle new digital services with traditional services.

Level 4 - Optimizing

The organization's digital initiatives within the dimension are being fine-tuned and used to further increase overall performance.

C4.1 Customer experience management has moved from reactive to proactive including automated actions (e.g., next-best action, personalized promotions).

C4.2 Data analytics are being extensively used to improve customer value, including development of new services offerings, promotions, and branding.

C4.3 Digital tools and systems are enabling full customization of services at the individual customer level, including third-party products.

C4.4 Initial tests of data-driven dynamic are is ongoing.

Level 5 - Pioneering

The organization is breaking new ground and advancing the state of the practice within the dimension.

C5.1 Dynamic pricing is being used to maximize customer value through full personalisation and flexibility.

C5.2 Machine learning and other advanced tools are being used to identify consumption trends and to develop new services and pricing strategies that are entirely new to the industry.

C5.3 New (including non-traditional telecommunication) digital services are being developed based on deep knowledge of customer (e.g., advanced analytics) and are, from inception, fully integrated across all touch points (e.g., one screen/app/bill for all services). 


\title{
A Digital Maturity Model for Telecommunications Service Providers
}

\author{
Omar Valdez-de-Leon
}

Appendix 1. Characteristics of the digital maturity model for telecommunications service providers (Page 4 of 7 )

\section{Ecosystem}

This dimension focuses on partner ecosystem development and fostering as a key element for a digital business.

Level 1 - Initiating

The organization has decided to move toward a digital business and is taking initial steps in that direction.

E1.1 The organization has developed a preliminary ecosystem strategy for digital services.

E1.2 Programs and key assets (e.g., people, technology platforms) have been identified that will form the basis for a digital ecosystem.

E1.3 Resources (e.g., people and funding) are being allocated to develop a digital ecosystem.

Level 2 - Enabling

The organization is implementing initiatives within the dimension that will form the foundation of its digital business.

E2.1 An ecosystem strategy, as part of a wider digital product strategy, has been signed-off by senior management.

E2.2 An initial group of partners has been on-boarded, albeit with limited integration of products and capabilities (e.g., on a re-seller model).

E2.3 Tools and systems are being put in place to support a closer integration of partners, including service enablement platforms, APIs, and preferred pricing structures.

Level 3 - Integrating

The organization's initiatives are being integrated across the organization to support end-to-end capabilities.

E3.1 The ecosystem strategy has evolved to focus on developing a two-sided model whereby value is created for both end customers and partners.

E3.2 Integration with partners goes beyond basic product bundling or re-selling, including some resource sharing (e.g., joint market channels).

E3.3 Investments in integration capabilities are being made to facilitate fast and efficient partner service development.

E3.4 The organization is integrating partner services and capabilities to enhance existing products.

Level 4 - Optimizing

The organization's digital initiatives within the dimension are being fine-tuned and used to further increase overall performance.

E4.1 The ecosystem strategy has moved towards a digital marketplace where users can integrate services from various ecosystem parties.

E4.2 Dedicated teams are in place to help develop partner capabilities (e.g., designating marketing resources to help partners to develop their promotions and go-to-market strategies).

E4.3 Investments in integration and development capabilities are being made to not only enable but accelerate and reduce costs of service creation by partners in ecosystem.

E4.4 Data flows across the ecosystem partners for product/service optimization.

Level 5 - Pioneering

The organization is breaking new ground and advancing the state of the practice within the dimension.

E5.1 The ecosystem is mature and it starts producing innovations that cross organizational boundaries.

E5.2 Products and services developed and launched in partnership with ecosystem partners are leading the market and are based on data-driven customer knowledge shared across partner organizations.

E5.3 The organization is developing new revenue streams and business models that incorporate ecosystem partners from inception through to launch and operation. 


\title{
A Digital Maturity Model for Telecommunications Service Providers
}

\author{
Omar Valdez-de-Leon
}

Appendix 1. Characteristics of the digital maturity model for telecommunications service providers (Page 5 of 7 )

\begin{abstract}
5. Technology
This dimension is focused on the capabilities that enable an effective technology planning, deployment, integration, and use to support the digital business.
\end{abstract}

Level 1 - Initiating

The organization has decided to move toward a digital business and is taking initial steps in that direction.

T1.1 A digital-specific, IT architecture is being developed.

T1.2 Efforts to define required transformation of IT architecture have been started.

T1.3 Some initial pilots are planned to test new digital tools and platforms.

Level 2 - Enabling

The organization is implementing initiatives within the dimension that will form the foundation of its digital business.

T2.1 A digital-specific IT architecture has been defined and changes to enterprise IT are ongoing to align it to target architecture. Tactical IT investment plans are aligned to target architecture.

T2.2 Platforms are being deployed to support digital services (e.g., an Internet of Things, or IoT, platform).

T2.3 An integral API and security strategy for supporting third-party services has been defined.

T2.4 Support systems are being implemented to support digital services (e.g., flexible charging and billing).

T2.5 There is a process to evaluate IT investments based on their alignment to the digital strategy of the organization.

Level 3 - Integrating

The organization's initiatives are being integrated across the organization to support end-to-end capabilities.

T3.1 Digital enterprise IT architecture has been largely implemented, including consolidation of stove-pipe systems into platforms for support of omni-channel and third-party services.

T3.2 Third-party services are being integrated and supported by digital enterprise IT architecture and related tools.

T3.3 Processes across the organization (e.g., customer support, partner onboarding) are aligned to digital IT architecture.

T3.4 Analytics technologies are being implemented to facilitate data collection and sharing across functions.

Level 4 - Optimizing

The organization's digital initiatives within the dimension are being fine-tuned and used to further increase overall performance.

T4.1 End-to-end processes supporting digital services are being optimized by leveraging the digital enterprise IT architecture.

T4.2 Integration tools are deployed to reduce time and costs of integration of third-party services.

T4.3 Digital IT architecture supports business agility through flexible tools and supporting processes.

T4.4 Analytics technologies are being used for optimization of services and processes.

T4.5 Automation of processes using real-time data processing is being used for proactive decision making across the organization.

Level 5 - Pioneering

The organization is breaking new ground and advancing the state of the practice within the dimension.

T5.1 Technologies such as advanced data analytics underpin innovation processes across the organization, from new service development through to service assurance to customer support.

T5.2 Automation throughout the organization drives superior performance (e.g., speed, reliability, ARPU, NPS) compared to industry peers.

T5.3 Tools using technology such as machine learning are implemented and used across the organization (and even to ecosystem partners) for predictive activities (e.g., service reliability, user consumption trends) that support digital business innovation. 


\title{
A Digital Maturity Model for Telecommunications Service Providers
}

\author{
Omar Valdez-de-Leon
}

Appendix 1. Characteristics of the digital maturity model for telecommunications service providers (Page 6 of 7 )

\section{Operations}

This dimension focuses on the capabilities that support the service provision. Increased maturity within this dimension demonstrate a more digitized, automated, and flexible operation.

Level 1 - Initiating

The organization has decided to move toward a digital business and is taking initial steps in that direction.

O1.1 Investments to automate key operations that support digital services (e.g., service provisioning, charging, and billing) are being evaluated.

O1.2 Improvements in network visibility and automation are being evaluated.

O1.3 Initiatives to update key business processes to support digital services have been identified.

Level 2 - Enabling

The organization is implementing initiatives within the dimension that will form the foundation of its digital business.

O2.1 Systems to support and automate digital services are being implemented.

O2.2 Advanced analytics are being deployed for service assurance improvements.

O2.3 Systems and processes to collect and analyze customer usage data are being deployed.

O2.4 Processes and policies to better support digital services are being designed and implemented in some key areas of the organization (e.g., ordering, fulfilment, partner management).

Level 3 - Integrating

The organization's initiatives are being integrated across the organization to support end-to-end capabilities.

O3.1 Automation of end-to-end processes is being implemented to support digital services..

03.2 Network data is being actively collected, including user- and partner-contributed data, to improve network visibility and to assist expansion planning.

03.3 Processes and systems are in place to support integration of third-party digital services.

O3.4 Network, customer, and other usage data is being collected and combined to provide visibility of end-to-end processes across the organization.

O3.5 Digital services are implemented and deployed jointly with traditional ones, and they share processes.

Level 4 - Optimizing

The organization's digital initiatives within the dimension are being fine-tuned and used to further increase overall performance.

O4.1 Automated processes are being optimized to improve efficiency and reduce costs of designing, provisioning, and supporting of digital services, including partner services.

O4.2 Real-time network, customer, and usage data is being combined and analyzed to optimize service reliability as well as key processes (e.g., customer support).

O4.3 Some real-time, automated decision making is being implemented in the service provision of digital services (e.g., if the event of service failure, send job order and customer-personalized message).

Level 5 - Pioneering

The organization is breaking new ground and advancing the state of the practice within the dimension.

O5.1 Full observability of service and usage data is now driving innovation within the organization, including dynamic offerings to both customers and partners.

05.2 Automated end-to-end processes ensure real-time data flows across functions for improved planning and decision making.

O5.3 Real-time, automated decision making is fully implemented in the service provision of digital services. 


\title{
A Digital Maturity Model for Telecommunications Service Providers
}

\author{
Omar Valdez-de-Leon
}

Appendix 1. Characteristics of the digital maturity model for telecommunications service providers (Page 7 of 7 )

\section{Innovation}

This dimension focuses on the capabilities that enable more flexible and agile ways of working that will form the basis for an effective digital business.

Level 1 - Initiating

The organization has decided to move toward a digital business and is taking initial steps in that direction.

I1.1 A need to develop a more agile and innovative organization has been identified.

I1.2 The organization is developing a strategy for digital innovation across functions.

11.3 Some initial changes are being made to the way digital services are developed with a focus hitherto on incremental improvements.

\section{Level 2 - Enabling}

The organization is implementing initiatives within the dimension that will form the foundation of its digital business.

I2.1 A digital innovation strategy has been developed with focus on agile development and open and data-driven innovation processes.

I2.2 Investments in digital technologies are aligned to innovation strategy and activities.

I2.3 New processes are being implemented to foster digital innovation.

I2.4 Investments in people development for digital innovation are underway.

Level 3 - Integrating

The organization's initiatives are being integrated across the organization to support end-to-end capabilities.

13.1 Open innovation with external parties including partners, users, and others has been implemented to support digital innovation.

I3.2 Data (including service, customer, and usage) is shared across the organization (and to partners) to support innovation.

I3.3 Metrics and key performance indicators specific to digital innovation and partner integration are being implemented.

Level 4 - Optimizing

The organization's digital initiatives within the dimension are being fine-tuned and used to further increase overall performance.

I4.1 Innovation in new digital services is mature, with clearly defined targets, processes, and performance metrics.

I4.2 Time to market of new service propositions is being reduced through well-established innovation processes.

I4.3 Customer and partner co-creation of new services is used to advance innovation and reduce costs of development.

Level 5 - Pioneering

The organization is breaking new ground and advancing the state of the practice within the dimension.

I5.1 The organization is breaking new ground in the way it innovates, establishing innovation processes that are new to the industry.

I5.2 The organization is recognized in the industry as leader in digital innovation.

I5.3 New digital services launched in the last 3 years account for a significant share of total digital revenues (e.g., $>30 \%)$ 